Louisiana State University

LSU Digital Commons

Faculty Publications

School of Animal Sciences

$10-15-2013$

\title{
AMP-activated protein kinase mediates myogenin expression and myogenesis via histone deacetylase 5
}

\author{
Xing Fu \\ Washington State University Pullman \\ Jun Xing Zhao \\ College of Animal Science and Veterinary Medicine \\ Junfang Liang \\ Washington State University Pullman \\ Mei Jun Zhu \\ Washington State University Pullman \\ Marc Foretz \\ Washington State University Pullman
}

See next page for additional authors

Follow this and additional works at: https://digitalcommons.Isu.edu/animalsciences_pubs

\section{Recommended Citation}

Fu, X., Zhao, J., Liang, J., Zhu, M., Foretz, M., Viollet, B., \& Du, M. (2013). AMP-activated protein kinase mediates myogenin expression and myogenesis via histone deacetylase 5. American Journal of Physiology - Cell Physiology, 305 (8) https://doi.org/10.1152/ajpcell.00124.2013

This Article is brought to you for free and open access by the School of Animal Sciences at LSU Digital Commons. It has been accepted for inclusion in Faculty Publications by an authorized administrator of LSU Digital Commons.

For more information, please contact ir@lsu.edu. 
Authors

Xing Fu, Jun Xing Zhao, Junfang Liang, Mei Jun Zhu, Marc Foretz, Benoit Viollet, and Min Du 


\title{
AMP-activated protein kinase mediates myogenin expression and myogenesis via histone deacetylase 5
}

\author{
Xing Fu, ${ }^{1 *}$ Jun-Xing Zhao, ${ }^{2 *}$ Junfang Liang, ${ }^{1}$ Mei-Jun Zhu, ${ }^{3}$ Marc Foretz, ${ }^{3,4,5}$ Benoit Viollet,,${ }^{4,5,6}$ \\ and Min Du' ${ }^{1}$ \\ ${ }^{1}$ Department of Animal Sciences, Washington State University, Pullman, Washington; ${ }^{2}$ College of Animal Science and \\ Veterinary Medicine, Shanxi Agriculture University, Taigu, Shanxi, China; ${ }^{3}$ School of Food Sciences, Washington State \\ University, Pullman, Wyoming; ${ }^{4}$ Institut National de la Santé et de la Recherche Médicale U1016, Institut Cochin, Paris, \\ France; ${ }^{5}$ Université Paris Descartes, Sorbonne Paris Cité, Paris, France; and ${ }^{6}$ Centre National de la Recherche Scientifique \\ Unité Mixte de Recherche 8104, Paris, France
}

Submitted 2 May 2013; accepted in final form 5 August 2013

Fu X, Zhao JX, Liang J, Zhu MJ, Foretz M, Viollet B, Du M. AMP-activated protein kinase mediates myogenin expression and myogenesis via histone deacetylase 5. Am J Physiol Cell Physiol 305: C887-C895, 2013. First published August 7, 2013; doi:10.1152/ajpcell.00124.2013.There is a global epidemic of obesity, and obesity is known to inhibit AMP-activated protein kinase (AMPK) activity and impairs myogenesis. Myogenin mediates the fusion of myoblasts into myotubes, a critical step in myogenesis. We observed that inhibition of AMPK $\alpha 1$ downregulates myogenin expression and myogenesis, but the underlying mechanisms are unclear. We postulated that AMPK regulates myogenin expression through phosphorlytion of histone deacetylase 5 (HDAC5). In $\mathrm{C} 2 \mathrm{C} 12$ cells, HDAC5 knockdown increased while HDAC5 stablization by MC1568 reduced myogenin expression. Consistently, using luciferase assay, we observed that myogenin promoter activity was negatively regulated by HDAC5. Using RNA interference and primary myoblasts prepared from wild-type and AMPK $\alpha 1$ knockout mice, we further demonstrate that AMPK $\alpha 1$ regulates HDAC5 phosphorylation at Ser 259 and 498. Mutation of these two Ser to Ala in HDAC5 abolished the regulatory role of AMPK $\alpha 1$ on myogenin expression, clearly showing the necessity of these phosphorylation sites in mediating myogenin expression. In aggregate, these data show that AMPK inhibition downregulates myogenin transcription and myogenesis through phosphorylation of HDAC5, mediated mainly by AMPK $\alpha 1$. These data demonstrate that AMPK is a key molecular target for promoting myogenesis and muscular regeneration. Because drugs activating AMPK activity, such as metformin, are widely available, our finding has critical clinical implications to ensure proper muscle development and regeneration in obese subjects and under other pathophysiological conditions where AMPK activity is attenuated.

AMPK; histone deacetylase; myogenin; myogenesis; obesity; phosphorylation

SKELETAL MUSCLE, WHICH COMPRISES $\sim 40 \%$ of the body mass of adults, is the main peripheral tissue responsive to insulin stimulated uptake of glucose (21) and critical in the development of type 2 diabetes (23). Skeletal muscle hyperplasia occurs during the fetal stage while postnatal growth is primary due to hypertrophy, both of which involve extensive myogenesis. Downregulation of myogenesis during the fetal stage permanently reduces the number of muscle fibers in later life, reducing muscle mass and contraction force $(1,3,15)$. Con-

\footnotetext{
* X. Fu and J.-X. Zhao contributed equally to this work.

Address for reprint requests and other correspondence: M. Du, Dept. of Animal Sciences, Washington State Univ., Pullman, WA 99164 (e-mail:
} min.du@wsu.edu). sistently, attenuated myogenic differentiation and fusion of satellite cells lead to muscular atrophy, impairing normal muscular functions $(2,6,10)$.

Obesity is increasing at an alarming pace with a current obesity rate at $>30 \%$ and another $30 \%$ overweight in the United States (12). It has been well demonstrated that obesity and its associated chronic inflammation inhibit AMP-activated protein kinase (AMPK) activity $(9,11,20,41)$. Our previous studies show that low AMPK activity is correlated with attenuated myogenic differentiation during early muscle development $(43,46,49)$. In addition, AMPK constitutively active mutation in Rendement Napole (RN) pigs is associated with enhanced muscle growth in this pig breed $(29,32)$. These data show the positive association between AMPK and myogenesis, but the causal relationship remains to be established. AMPK is a heterotrimeric enzyme, composed of $\alpha-, \beta$-, and $\gamma$-subunits, which plays an important role in energy metabolism $(16,19$, $36)$. The catalytic $\alpha$-subunit of AMPK has two isoforms, $\alpha 1$ and $\alpha 2$, which display differential expression during myogenic cell differentiation (31). Knockout of either $\alpha 1$ - or $\alpha 2$-subunit results in visually normal mice, but knockout of both $\alpha 1$ and $\alpha 2$-subunits is lethal around embryonic day 9.5 (45), showing that $\alpha 1$ and $\alpha 2$ have compensatory roles in regulating fetal growth and development. Currently, there is no direct evidence detailing the AMPK isoform-specific role in myogenesis.

Cell differentiation and tissue development are controlled by epigenetic modifications, including histone and DNA modifications $(33,38)$. Histone acetylation activates gene expression $(24,28)$, which is regulated by histone acetyltransferase and histone deacetylase (HDAC; Ref. 40). HDAC5 belongs to the class IIa HDAC family and acts as a conserved transcriptional repressor through interaction with myocyte enhancer factor-2 (MEF2) (4). The activity of HDAC5 is mainly regulated through phosphorylation by several kinases $(14,27,48)$. Myogenin is necessary for myoblast fusion into myotubes, a critical step in myogenesis $(8,37)$. The myogenin promoter contains a MEF2 binding site (17), which prompted us to hypothesize that AMPK activity is necessary for myogenesis through a process mediated by HDAC5 and MEF2 and that an AMPK isoformspecific mechanism exists. Our data demonstrated that AMPK $\alpha 1$ but not AMPK $\alpha 2$ stimulates myogenin expression and myogenesis via phosphorylation of HDAC5 at Ser 259 and 498, which provides an important mechanisms linking AMPK to myogenic differentiation. 


\section{MATERIALS AND METHODS}

Animal experiments. All animals were handled in accordance with protocols approved by the Animal Use and Care Committees of Washington State University (Permit No. 04158). Wild-type (WT) C57BL/6 mice were obtained from Jackson Laboratory (Bar Harbor, $\mathrm{ME}) . \mathrm{AMPK} \alpha 1^{-1-} 129 \mathrm{~S} 2 / \mathrm{SvPas}[\mathrm{AMPK} \alpha 1$ knockout $(\mathrm{KO})]$ and $\mathrm{AMPK} \alpha 2^{-1-} \mathrm{C} 57 \mathrm{BL} / 6(\mathrm{AMPK} \alpha 2 \mathrm{KO})$ mice were generated as previously described $(18,44)$.

Antibodies and chemicals. Antibodies against HDAC5 (no. 2082), phospho-HDAC5 at Ser 259 (no. 3443), phospho-HDAC5 at Ser 498 (no. 3424), tag (no. 2368), mouse IgG (no. 7076), $\beta$-tubulin (no. 2146), histone H3K9 (no. 9649), goat anti-mouse Alexa Fluor 555 (no. 4409), goat anti-rabbit Alexa Fluor 488 (no. 4412), and goat anti-rabbit Alexa Fluor 555 (no. 4413) antibodies were purchased from Cell Signaling (Danvers, MA). Rabbit anti-desmin antibody (ab15200) was purchased from Abcam (Cambridge, MA). Antimyogenin (F5D) and anti-myosin heavy chain (anti-MHC; MF20) mouse monoclonal antibodies were obtained from the Developmental Studies Hybridoma Bank (Iowa City, IA). IRDye 800CW goat antirabbit secondary antibody and IRDye 680 goat anti-mouse secondary antibody were purchased from LI-COR Biosciences (Lincoln, NE). Puromycin were purchased from Sigma (St. Louis, MO). MC1568 was purchased from Selleck (Houston, TX). pGL4 promoter luciferase plasmid was purchased from Promega (Madison, WI). Lipofectamine was purchased from Invitrogen (Carlsbad, CA).

Cell culture. Myogenic C2C12 cells were grown at $37^{\circ} \mathrm{C}$ with $5 \%$ $\mathrm{CO}_{2}$ in DMEM supplemented with $10 \%$ FBS and $1 \%$ antibiotic mixture. Primary myoblasts were extracted from neonatal mice following a procedure described previously with modifications (35). Briefly, muscle from hindlimbs was minced and digested in DMEM with collagenase D and Dispase II (Roche Diagnostics, Mannheim, Germany) at $37^{\circ} \mathrm{C}$ for $\sim 30 \mathrm{~min}$. The slurry was then passed through a $100-\mu \mathrm{m}$ cell strainer. Cells were collected by centrifuge at $350 \mathrm{~g}$ for 5 min. The cell pellet was then resuspended in F-10 with $20 \%$ FBS and $1 \%$ antibiotic mixture. Primary myoblasts were seeded on collagen-coated plates and enriched by preplating. The purity of enriched primary myoblasts was checked by FACS and immunocytochemistry using anti-desmin antibody. When cells reached $100 \%$ confluence, the culture medium was switched to DMEM supplemented with $2 \%$ horse serum and $1 \%$ antibiotic mixture to induce myogenic differentiation. Myogenin mRNA expression, myogenin protein content, and MHC were analyzed at 2, 3, and 6 days after inducing myogenesis respectively.

Immunoblotting analyses. Immunoblotting analysis was performed as previously described using an Odyssey Infrared Imaging System (LI-COR Biosciences, Lincoln, NE; Ref. 48). Band density was normalized to $\beta$-tubulin content.

Real-time quantitative PCR. Total RNA was extracted using Trizol (Sigma) followed by DNase (NEB, Ipswich, MA) treatment, and cDNA was synthesized using a reverse transcription kit (Bio-Rad, Hercules, CA). Real-time quantitative PCR (RT-PCR) was carried out using CFX RT-PCR detection system (Bio-Rad) with a SYBR Green RT-PCR kit from Bio-Rad. The following cycle parameters were used: 34 three-step cycles of $95^{\circ} \mathrm{C}, 20 \mathrm{~s} ; 55^{\circ} \mathrm{C}, 20 \mathrm{~s}$; and $72^{\circ} \mathrm{C}, 20 \mathrm{~s}$. Primer sequences and their respective PCR fragment lengths were as follows: Myogenin (97 bp), forward 5'-GAGATCCTGCGCAGCGCCAT-3', and reverse 5'-CCCCGCCTCTGTAGCGGAGA-3'; and 18S rRNA (110 bp), forward 5'-TGCTGTCCCTGTATGCCTCT-3', and reverse 5'-TGTAGCCACGCTCGGTCA-3'. After amplification, a melting curve $\left(0.01^{\circ} \mathrm{C} / \mathrm{s}\right)$ was used to confirm product purity, and agarose gel electrophoresis was performed to confirm that only a single product of the right size was amplified. Relative mRNA content was normalized to $18 \mathrm{~S}$ rRNA content.

Construction of expression vector. The myogenin promoter fragment containing the MEF2 binding site was amplified from mouse genomic DNA using the following primers: forward 5'- CTAGCTAGCCGTC-
CGTCCAAGACAACCC-3', and reverse 5'- CCGCTCGAGCAGGTCGGAAAAGGCTTGTT-3'. PCR products were subcloned between Xhol and Nhel sites of the pGL4-promoter-luciferase plasmid. The construct was verified by digestion with restriction enzymes and sequencing.

Transfection. Plasmid transfection of $\mathrm{C} 2 \mathrm{C} 12$ was performed using Lipofectamine according to the manufacturer's instructions. Briefly, $12 \mathrm{~h}$ before transfection, cells were switched to medium without antibiotics. Transfections were carried out when cells reached $95 \%$ confluence, using a 1:3 ratio of DNA $(\mu \mathrm{g})$ :Lipofectamine $(\mu \mathrm{l})$; medium was switched to DMEM medium containing 10\% FBS and 1\% antibiotics $12 \mathrm{~h}$ following transfection. For short hairpin (sh)RNA interference, AMPK $\alpha 1$ shRNA, AMPK $\alpha 2$ shRNA, HDAC5 shRNA, and control shRNA (Santa Cruz Biotech, Santa Cruz, CA) were delivered into cells, and transfected cells were selected with puromycin $(2 \mu \mathrm{g} / \mathrm{ml})$. For HDAC5 overexpression, C2C12 cells were transfected with HDAC5 expression vectors, FLAG-HDAC5WT, FLAG-HDAC5-S259A, FLAG-HDAC5-S498A, and FLAGHDAC5-S259A/S498A (catalog no. 32213, 32214, 32215, and 32216; Addgene, Cambridge, MA). C2C12 cells transfected with green fluorescent protein (GFP) expression vector and nontransfected C2C12 cells were used as controls.

Plasmid transfection of primary myoblasts was performed using neon transfection system from Life Technologies (Grand Island, NY) following the manufacturer's suggested protocol with slight modifications. Briefly, $5 \times 10^{5}$ primary myoblasts were resuspended in 100 $\mu \mathrm{l}$ resuspension buffer and mixed with $5 \mu \mathrm{g}$ of each plasmid. The mixture was then loaded to the system. Transfection was performed with the following parameters: pulse voltage $(1,500 \mathrm{~V})$, pulse width $(10 \mathrm{~ms})$, and pulse number (3). Transfected primary myoblasts were then cultured in F-10 with $20 \%$ FBS and $1 \%$ antibiotic mixture.

Luciferase reporter activity assay. To measure the transcriptional activity of the myogenin promoter, $\mathrm{C} 2 \mathrm{C} 12$ cells were transfected with different expression vectors. Renilla luciferase vector (Promega, Madison, WI) was transfected as an internal control, and each transfection assay was performed at least six times. An equal amount of plasmids was used for all treatments. At $24 \mathrm{~h}$ following transfection, cells were harvested, and luciferase activity was measured using a dual luciferase assay kit (Promega) according to the manufacturer's instructions. Data from each experiment were normalized to the Renilla luciferase activity (48).

FACS. Cells were fixed in $4 \%$ PFA for $10 \mathrm{~min}$ at $37^{\circ} \mathrm{C}$, permeabilized in ice-cold methanol for $30 \mathrm{~min}$, and washed in PBS with $1 \%$ BSA. Then, $5 \times 10^{5}$ cells in PBS with $1 \%$ BSA were stained with rabbit anti-desmin primary antibody for $1 \mathrm{~h}$, washed, and stained with goat anti-rabbit Alexa Fluor 555 secondary antibody for $30 \mathrm{~min}$. Stained cells were sorted on FACSaria (BD Biosciences, San Jose, CA) and analyzed by FlowJo (Treestar, San Carlos, CA).

Immunocytochemical staining. Cells grown on coverslips were fixed in $4 \%$ paraformaldehyde for $10 \mathrm{~min}$, permeabilized with ice-cold methanol for $5 \mathrm{~min}$, quenched with $0.1 \%$ sodium borohydride for 5 min, and incubated with anti-MHC, anti-desmin, or mouse IgG $(1: 100)$ at $4^{\circ} \mathrm{C}$ overnight. Fluorescent secondary antibody $(1: 1,000)$ was then added, and stained cells were incubated at room temperature for $1 \mathrm{~h}$. Fluorescence was examined using a Leica inverted microscope (48).

Muscle fiber counting, muscle fiber area measure, muscle mass measure, and head-to-tail length measure. Two-month-old WT mice, $\mathrm{AMPK} \alpha 1 \mathrm{KO}$ mice, and $\mathrm{AMPK} \alpha 2 \mathrm{KO}$ mice were killed using $\mathrm{CO}_{2}$. Body weight and head-to-tail length were measured. Tibialis anteria (TA) muscle were weighed. Soleus muscle were isolated, fixed in $4 \%$ paraformaldehyde, and embedded in paraffin. Embedded tissue were sectioned (6- $\mu \mathrm{m}$ thick) and stained with hematoxylin and eosin. Cross sections with similar distance to the distal end of muscle were analyzed using Image pro plus (Media Cybernetics, Rockville, MD) to determine muscle fiber number and area. 
Statistics. For all studies, at least three independent experiments were conducted. All data are expressed as means \pm SE. Data were analyzed using the general linear model of SAS (SAS Institute, Cary, NC), and Tukey's Studentized range test was used to determine significance of differences among means. $P<0.05$ was considered significant.

\section{RESULTS}

HDAC5 regulates myogenin expression and myogenesis. HDAC5 regulates gene transcription through interaction with MEF2 (22), and a conserved MEF2 binding site on the myogenin promoter has been identified (17). To investigate whether HDAC5 regulates myogenin mRNA transcription, we used HDAC5 shRNA to knock down endogenous HDAC5. We found that HDAC5 knockdown increased myogenin mRNA levels (Fig. 1A). Myogenin and MHC protein levels were also increased as was $\mathrm{H} 3 \mathrm{~K} 9$ acetylation (Fig. $1 B$ ). Immunocytochemical staining further confirmed that more myotubes were formed by myocytes following HDAC5 knockdown compared with control shRNA transfected cells (Fig. 1C). To further investigate the role of HDAC5 on myogenin expression, HDAC5 was then overexpressed in C2C12 cells. As expected, myogenin protein level was decreased pronouncedly (Fig. 1D).

C2C12 cells were treated with MC1568 (5 $\mu \mathrm{M})$, a specific class II HDAC inhibitor, which stabilizes the repressor structure of HDAC5 (30). The myogenin mRNA level was decreased dramatically by the addition of MC1568 (Fig. 2A). In addition, MC1568 treatment decreased myogenin and MHC protein levels (Fig. 2B).
A
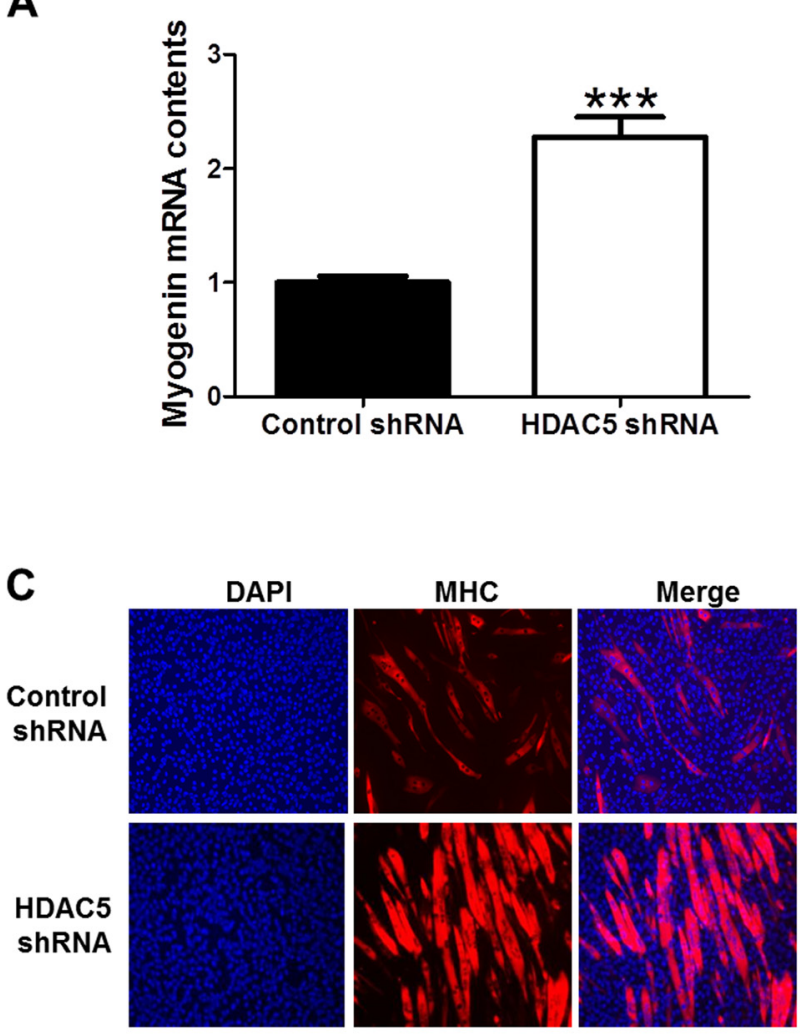

D

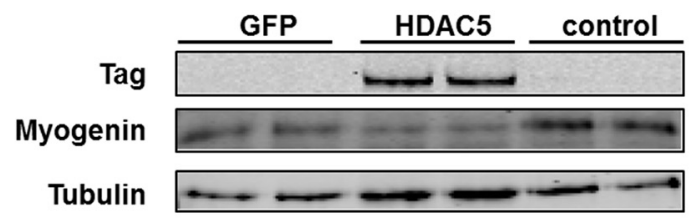

B
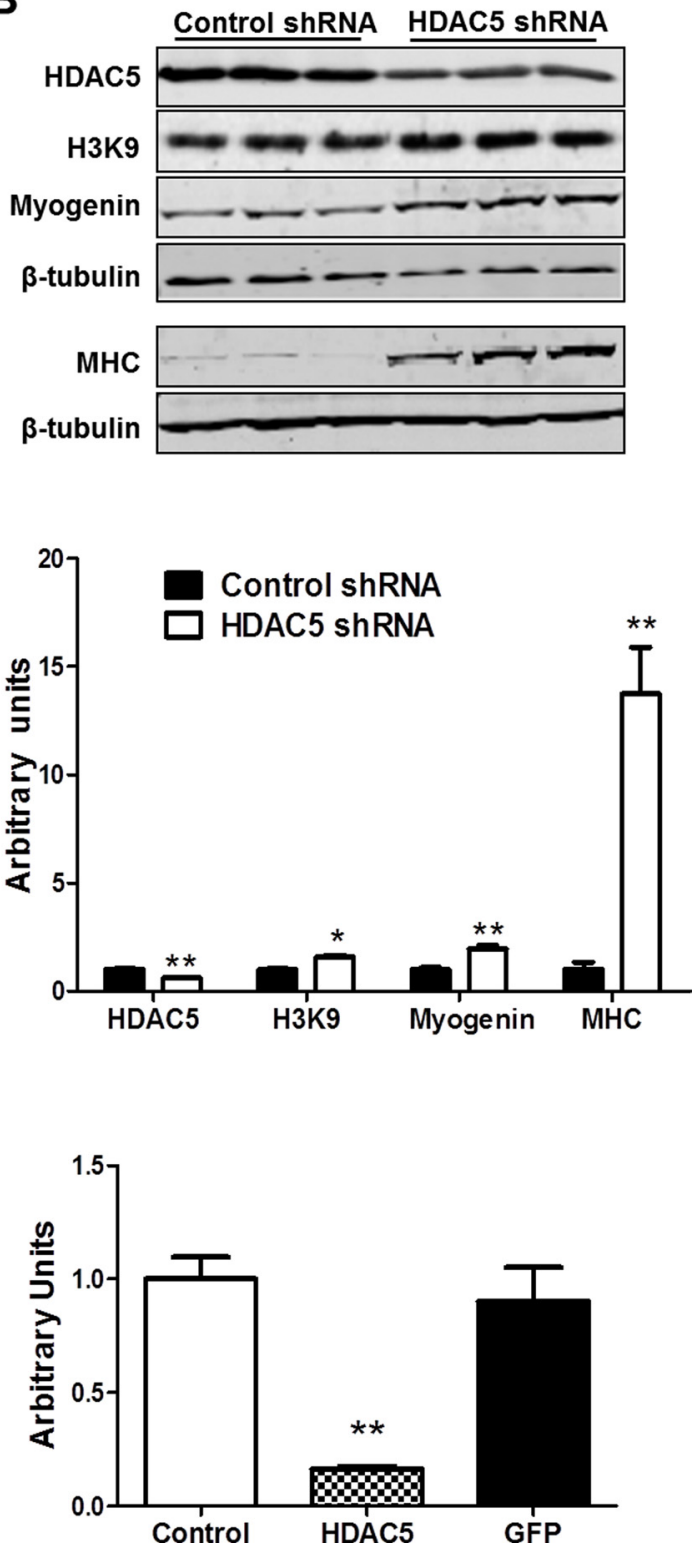

Fig. 1. Histone deacetylase 5 (HDAC5) regulated myogenin expression and myogenesis. A: myogenin mRNA content in C2C12 cells following HDAC5 knockdown. $B$ : HDAC5, H3K9, myogenin, and myosin heavy chain (MHC) protein content in $\mathrm{C} 2 \mathrm{C} 12$ cells following HDAC5 knockdown. $C$ : MHC immunocytochemical staining of myotubes formed by $\mathrm{C} 2 \mathrm{C} 12$ transfected with control short hairpin (sh)RNA and HDAC5 shRNA. D: myogenin protein level in C2C12 following HDAC5 overexpression. GFP, green fluorescent protein. ${ }^{*} P<0.05$ vs. control; $* * P<0.01$ vs. control; $* * * P<0.0001$ vs. control; means \pm SE; $n \geq 3$. 
A
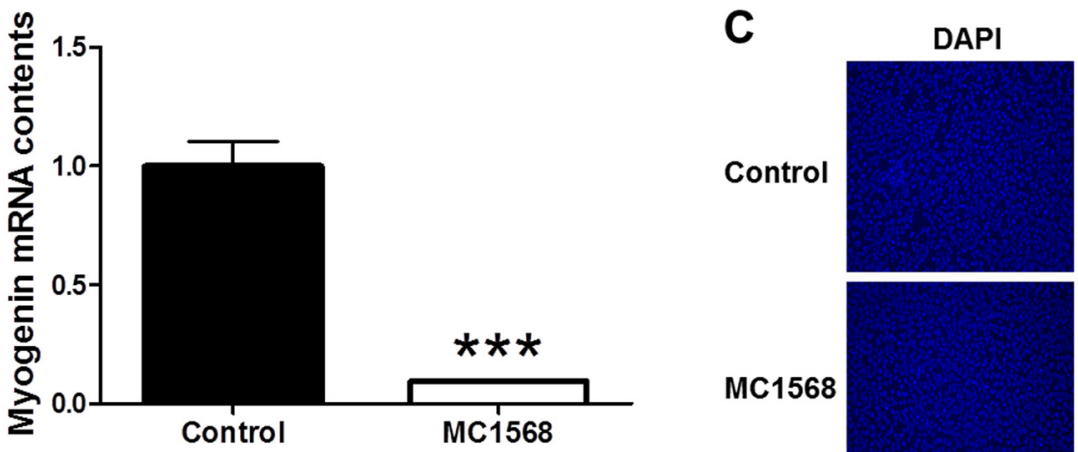

MHC

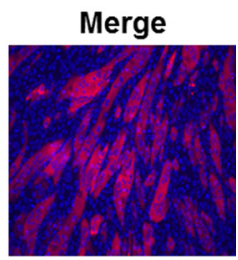

MC1568
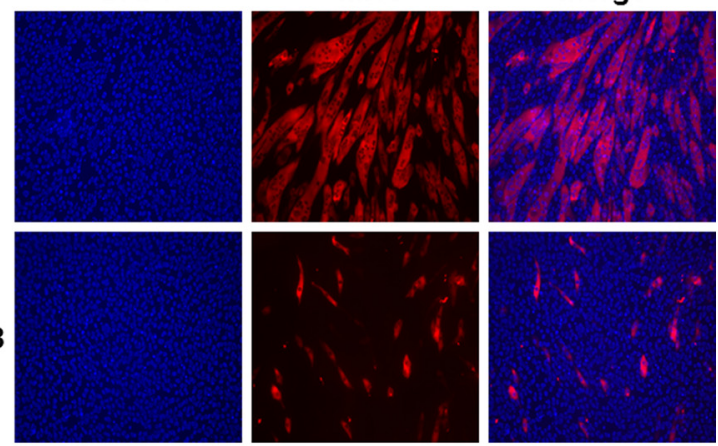

B
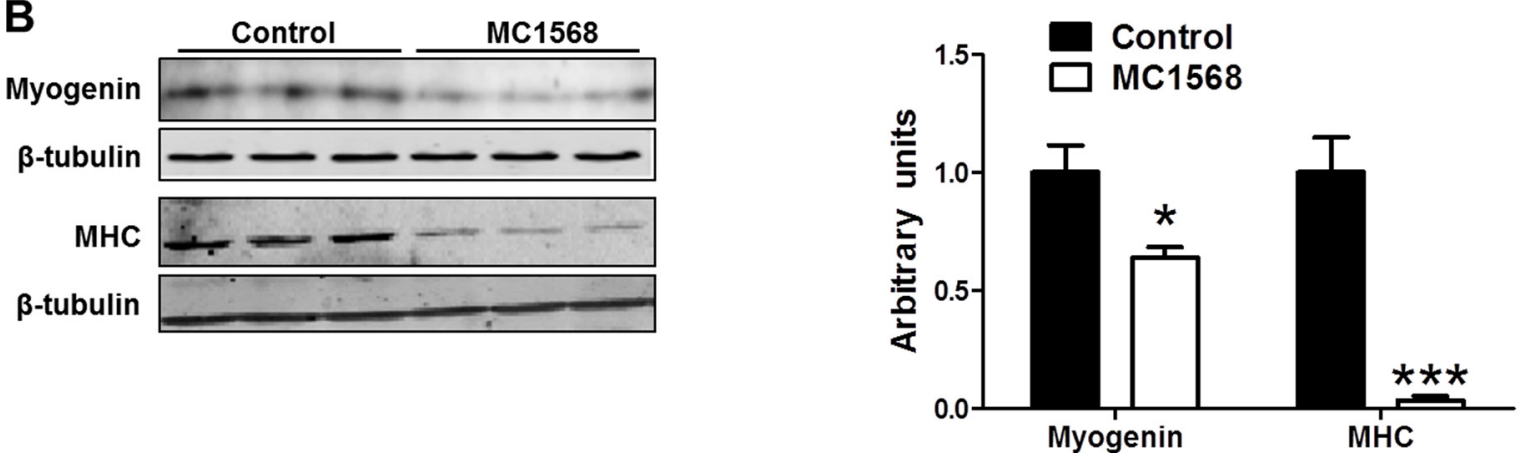

Fig. 2. HDAC5 stabilization by MC1568 reduced myogenin expression and myogenesis. C2C12 cells in myogenic differentiation medium supplemented with MC1568 $(5 \mu \mathrm{M})$ or vehicle (PBS). A: myogenin mRNA content analyzed by RT-PCR. $B$ : myogenin and MHC contents analyzed by immunoblotting. $C$ : MHC immunocytochemical staining of myotubes. $* P<0.05$ vs. control; $* * * P<0.0001$ vs. control; means \pm SE; $n \geq 3$.

As expected, MC1568 also decreased the number of mature myotubes compared with the control group (Fig. 2C).

The gene-specific deacetylation of HDAC5 is mediated by MEF2. To determine if HDAC5 regulates the transcriptional activity of the myogenin promoter, we cloned the myogenin promoter containing the MEF2 binding site into pGL4 luciferase vector to construct a myogenin promoter-driven luciferase reporter vector. $\mathrm{C} 2 \mathrm{C} 12$ cells transfected with the myogenin promoter-luciferase vector were cotransfected with the HDAC5 expression vector or GFP vector. Cells receiving
A

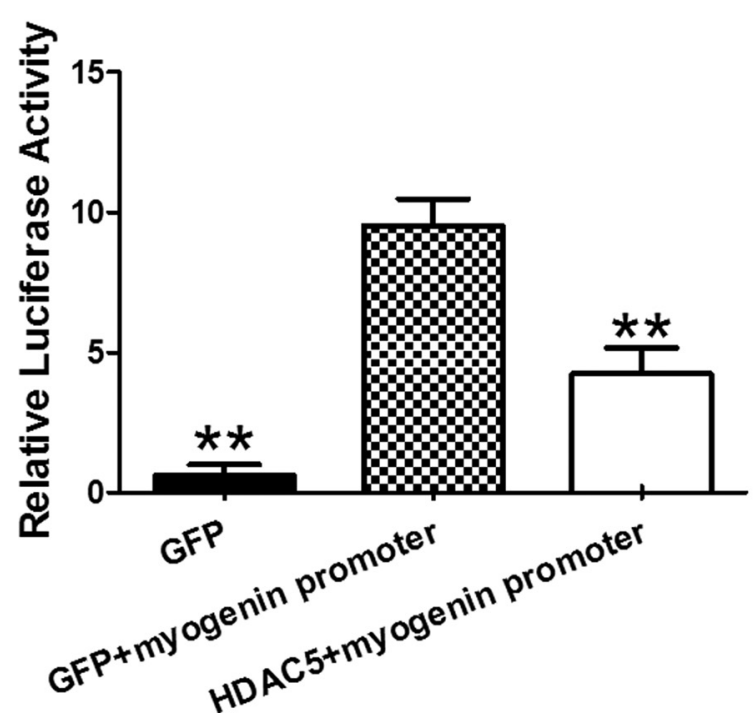

B

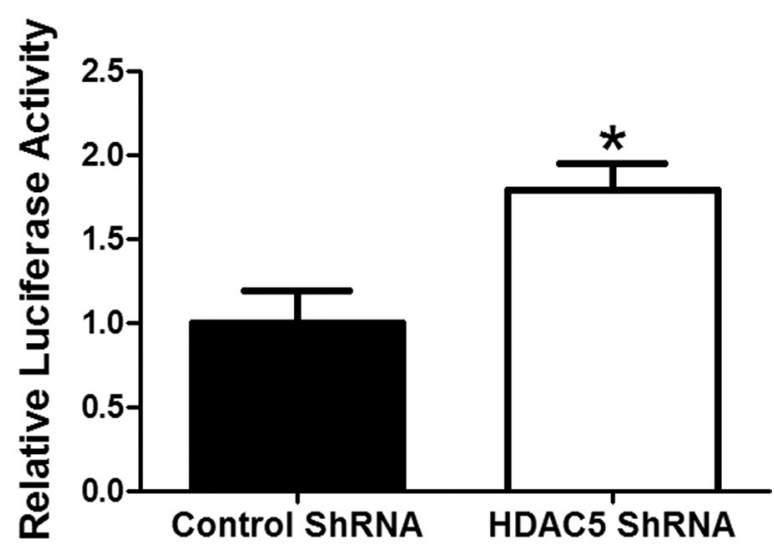

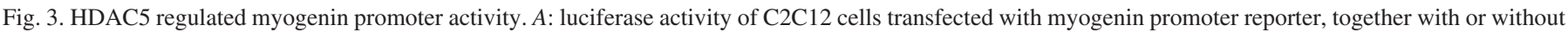

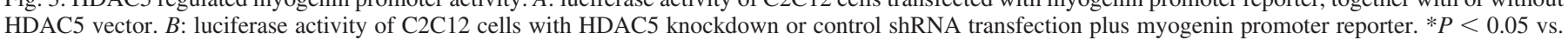
control; $* * P<0.01$ vs. control; means $\pm \mathrm{SE} ; n \geq 3$. 
the myogenin promoter-luciferase vector and GFP vector expressed higher luciferase activity than cells receiving myogenin promoter-luciferase vector and HDAC5 vector (Fig. $3 A$ ). Knockdown of endogenous HDAC5 by HDAC5 shRNA resulted in elevated luciferase activity (Fig. 3B), demonstrating that HDAC5 downregulates myogenin expression and myogenesis.

AMPK $\alpha 1$ phosphorylates HDAC5, necessary for mediating myogenin expression. To test the effects of reduced AMPK activity on phosphorylation of HDAC5, we isolated myoblasts from WT and AMPK $\alpha 1 \mathrm{KO}$ mice and tested the phophorylation level of HDAC5 Ser 259 and HDAC5 Ser 498, which are known to be phosphorylated by AMPK (26). We found that the phosphorylation of both HDAC5 Ser 259 and Ser 498 were reduced in AMPK $\alpha 1 \mathrm{KO}$ myoblasts (Fig. 4A). As expected the myogenin protein level was lower in TA muscle isolated from 2-mo-old AMPK $\alpha 1 \mathrm{KO}$ mice than that from 2-mo-old WT mice (Fig. $4 B$ ). WT and AMPK $\alpha 1$ KO primary myoblasts were isolated, enriched, and tested for purity by FACS and ICC using anti-desmin antibody (Fig. 4, $C$ and $D$ ). Enriched myoblasts were then induced for myogenic differentiation. We found that the myotube formation of AMPK $\alpha 1 \mathrm{KO}$ myoblasts was greatly reduced (Fig. 4E). To further test whether AMPK mediates myogenesis through HDAC5 in an isoform-specific manner, we transfected control cells and AMPK $\alpha 1$ knockdown cells with vectors expressing WT HDAC5, HDAC5 with Ser 259 mutated to Ala, or HDAC5 with Ser 498 mutated to Ala; Ser 259 and Ser 498 are two putative phosphorylation sites by AMPK. When transfected with WT HDAC5, AMPK $\alpha 1$ knockdown was associated with a lower myogenin content compared with the control group (Fig. 4F). In contrast, transfection with mutant HDAC5s blocked the downregulation of myogenin expression by AMPK knockdown, clearly showing the necessity of these phosphorylation sites in AMPK-regulated myogenin expression (Fig. 4G).

We further analyzed myogenin promoter-mediated luciferase activity. HDAC5 suppressed the transcriptional activity of the myogenin promoter in AMPK $\alpha 1$ knockdown cells;
A

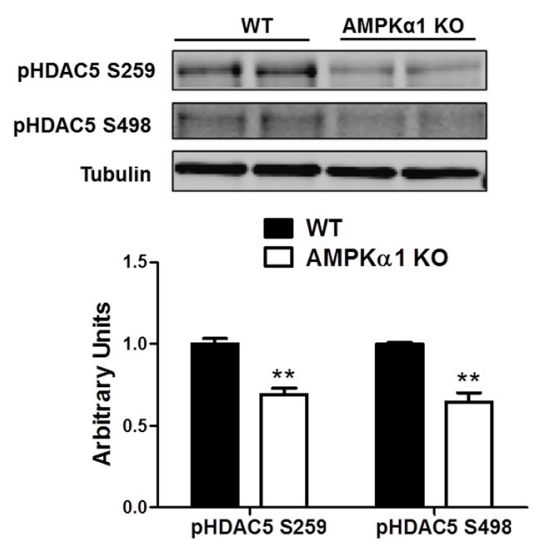

B
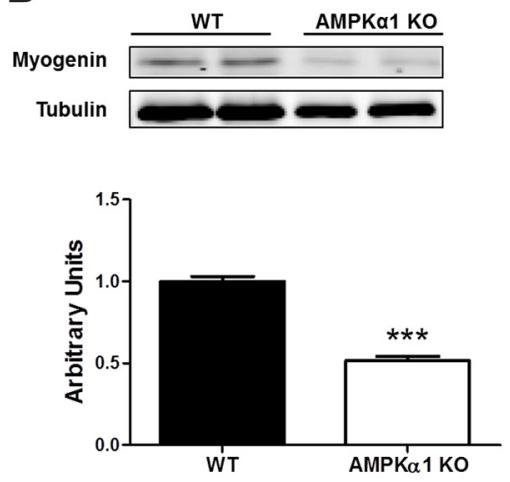

C

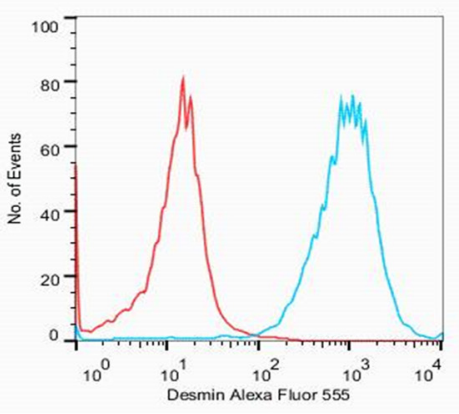

D
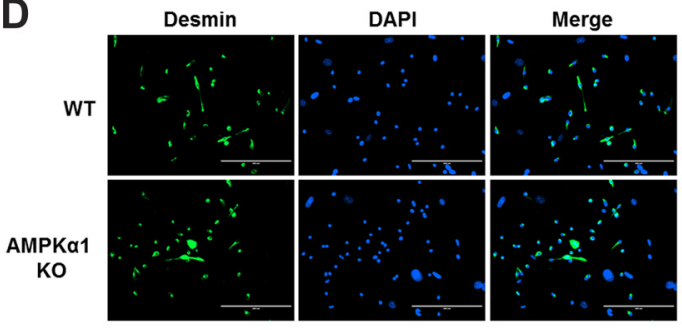

E
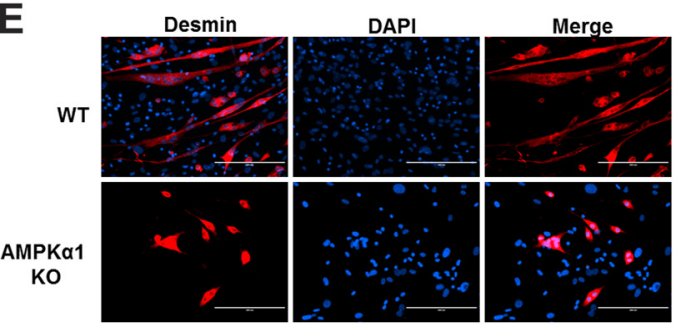

$\mathbf{F}$
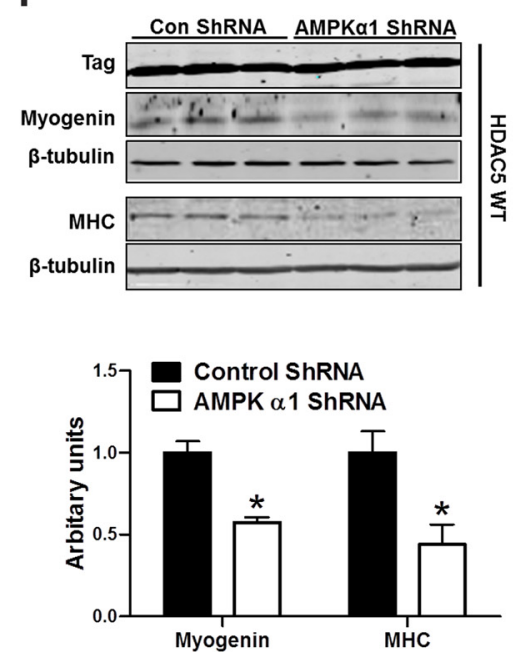

G
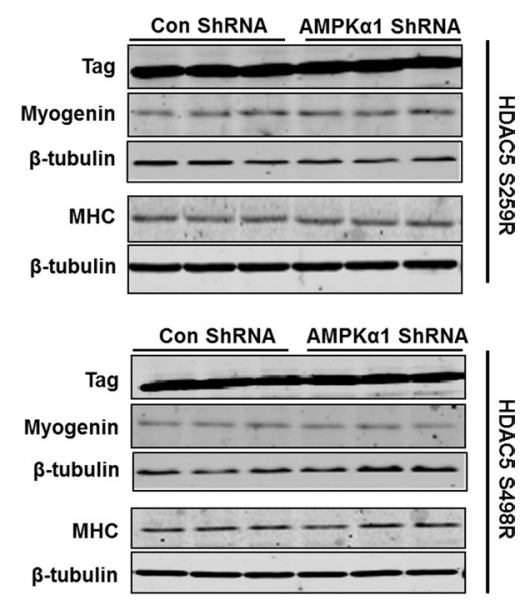

Fig. 4. AMP-activated protein kinase (AMPK) 1 enhances myogenesis through phosphorylating HDAC5 at Ser 259 and 498 . A: levels of HDAC5 phosphorylated at Ser 259 (S259) and Ser 498 (S259) in wild-type (WT) and AMPK 11 knockout (KO) myoblasts. B: myogenin protein level in tibialis anteria (TA) muscle isolated from 2-mo-old WT and AMPK $\alpha 1 \mathrm{KO}$ mice. $C-D$ : enriched myoblasts were tested for purity by FACS $(C)$ and immunocytochemistry $(D)$ using anti-desmin antibody. E: MHC immunocytochemical staining of myotubes formed by WT and AMPK $\alpha 1$ KO myoblasts. $F$ : myogenin and MHC levels in control, $\mathrm{C} 2 \mathrm{C} 12$, and $\mathrm{C} 2 \mathrm{C} 12$ cells with $\mathrm{AMPK} \alpha 1$ knockdown and transfected with WT HDAC5. G: myogenin and MHC levels in control, C2C12, and C2C12 cells with AMPK $\alpha 1$ knockdown and transfected with HDAC5 S259A (Ser 259 to Ala) and HDAC5 S498A (Ser 498 to Ala). $* P<0.05$ vs. control; $* * P<0.01$ vs. control; $* * * P<0.0001$ vs. control; means $\pm \mathrm{SE} ; n \geq 3$. 
this effect was absent in cells transfected with the HDAC5 mutants, further demonstrating that AMPK regulates myogenin expression through phosphorylation of HDAC5 (Fig. 5A).

We also analyzed myogenin mRNA expression. Consistently, AMPK $\alpha 1$ knockdown cells transfected with HDAC5 exhibited reduced myogenin mRNA contents; however, cells transfected with either HDAC5 mutant showed no change in myogenin mRNA contents (Fig. 5B). In aggregate, these data show that AMPK inhibition downregulates myogenin transcription and myogenesis through HDAC5 in C2C12 cells.

Enriched primary myoblasts were further transfected with myogenin promoter-luciferase vector together with WT HDAC5, HDAC5 S259A, HDAC5 S498A, or HDAC5 with both sites mutated (HDAC5 DM). WT HDAC5 significantly suppressed the activity of myogenin promoter in AMPK $\alpha 1 \mathrm{KO}$ primary myoblasts compared with WT primary myoblasts $(P<0.01)$. HDAC5 S259A suppressed the activity of myogenin promoter in $\mathrm{AMPK} \alpha 1 \mathrm{KO}$ primary myoblasts but to a lesser extent $(P<0.05)$. HDAC5 S498A caused a slight but not significant reduction in the activity of myogenin promoter. The HDAC5 double mutant failed to achieve any suppression in the activity of myogenin promoter compared with WT and AMPK $\alpha 1 \mathrm{KO}$ primary myoblasts (Fig. 5C). These data further confirmed that AMPK regulates HDAC5 through phosphorylation at S259 and S498 and these phosphorylations induce myogenin expression.

AMPK $\alpha 1$ KO mice had reduced muscle mass, less muscle fiber number and smaller muscle fiber diameter. Our in vitro studies have clearly established that AMPK $\alpha 1 \mathrm{KO}$ attenuated myogenesis via phosphorylation of HDAC5. If this notion is correct, we expect to see that $\mathrm{AMPK} \alpha 1 \mathrm{KO}$ mice has reduced muscle mass, less muscle fibers, and small muscle fiber size compared with those of WT mice. Indeed, the TA muscle in AMPK $\alpha 1 \mathrm{KO}$ mice was significantly smaller than that in WT mice. It should be noticed that the reduced muscle mass was due to smaller muscle diameter rather than reduced muscle length (Fig. 6A). The body weight of AMPK $\alpha 1 \mathrm{KO}$ mice was also found to be smaller than that of WT mice but no difference in head-to-tail length, indicating that the reduced body weight was mainly due to reduced muscle mass (Fig. 6B). As expected, the total number of fibers in the whole soleus muscle cross section of $\mathrm{AMPK} \alpha 1 \mathrm{KO}$ mice was $\sim 25 \%$ less than that
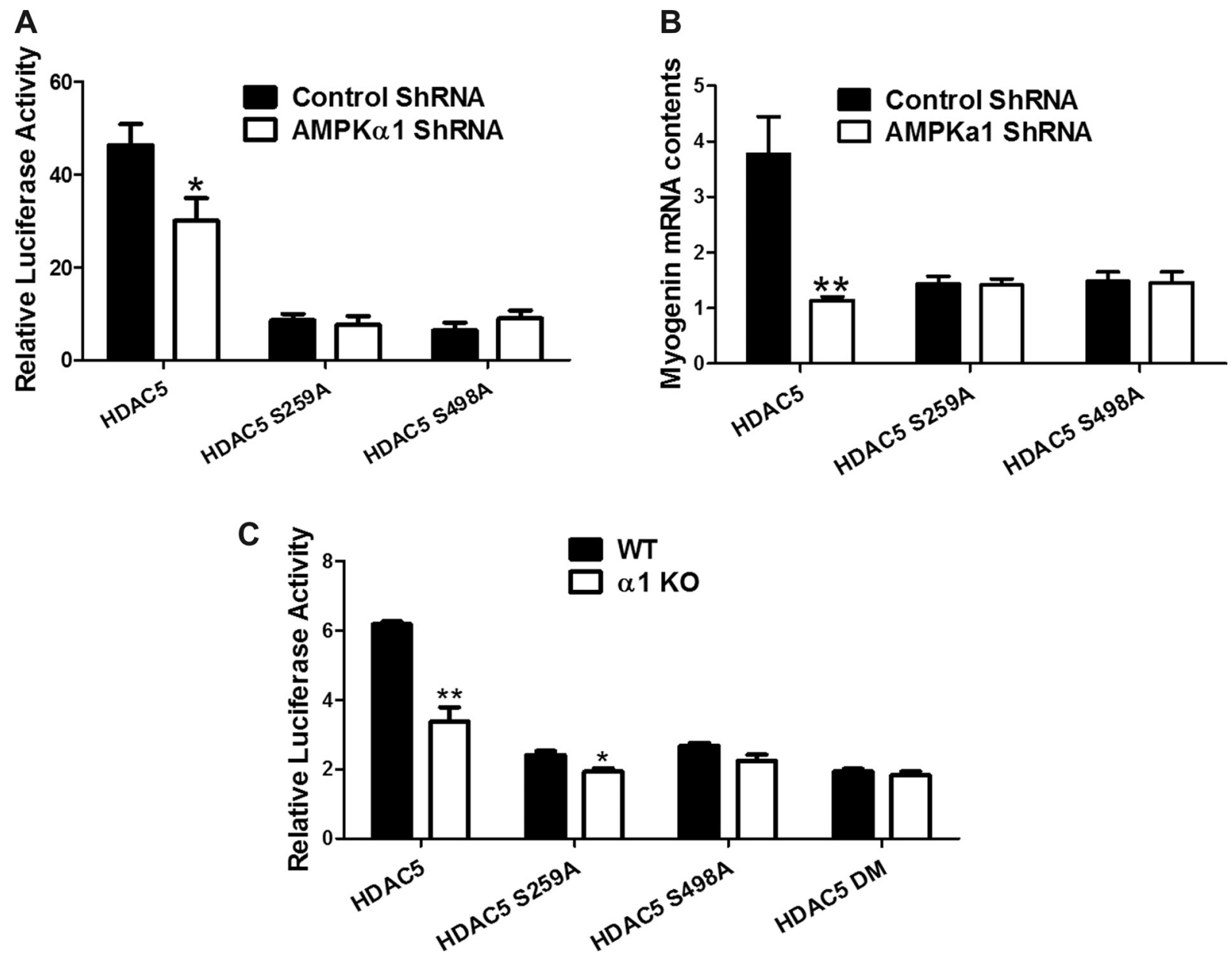

Fig. 5. Mutation on HDAC5 phosphorylation sites abolished the effect of AMPK on myogenin promoter activity. A: C2C12 cells were transfected with pGL4 myogenin + luciferase vector, either scramble or AMPK $\alpha 1$ ShRNA, together with HDAC5, HDAC5 S259A, or HDAC5 S498A. Myogenin promoter activity was monitored by luciferase activity. B: C2C12 cells were transfected with either scramble or AMPK $\alpha 1$ ShRNA, together with HDAC5, HDAC5 S259A, or HDAC5 S498A. Myogenin mRNA contents were tested by RT PCR. C: WT and AMPK $\alpha 1$ KO primary myoblasts were transfected with HDAC5, HDAC5 S259A, HDAC5 S498A, or HDAC5 DM (with both Ser 259 and Ser 498 mutated to Ala), together with pGL4 myogenin promoter reporter vector. Luciferase activity was analyzed. $* P<0.05$ vs. control; ${ }^{*} * P<0.01$ vs. control; means \pm SE; $n \geq 3$. 
A
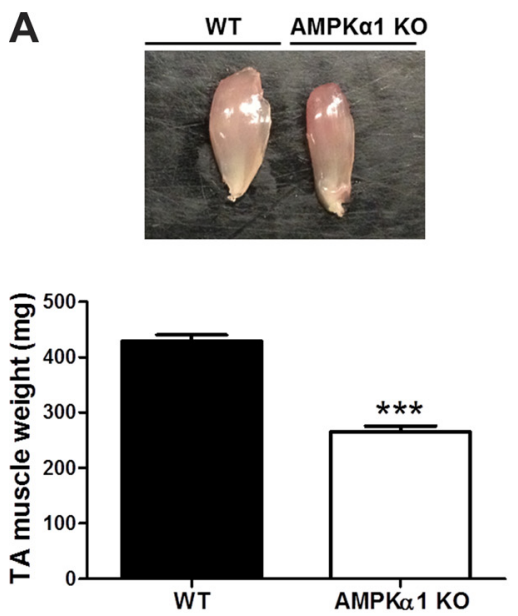

B

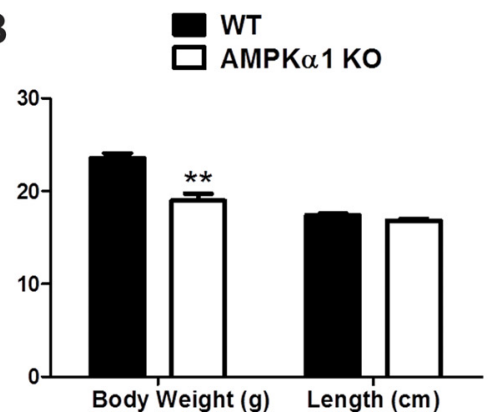

C
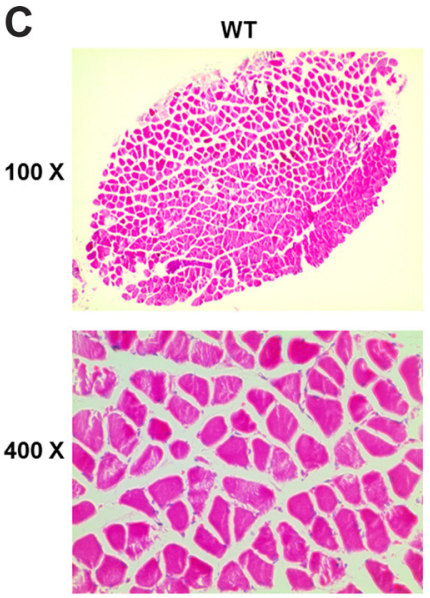

$C^{\prime}$

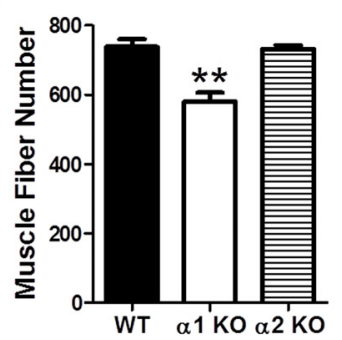

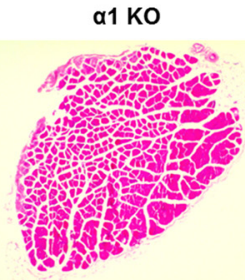
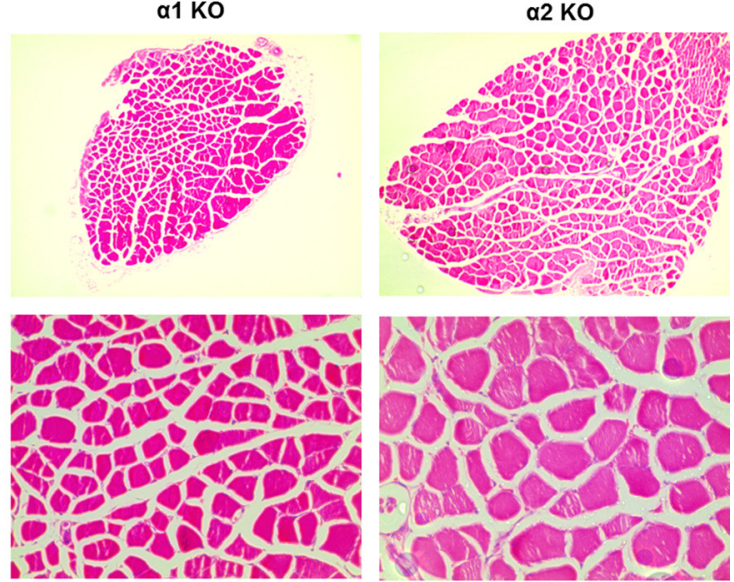

C"'

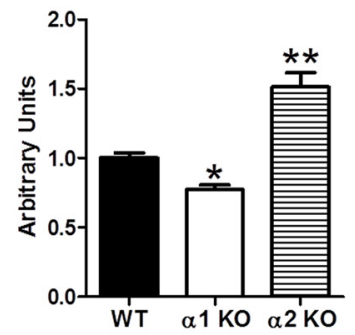

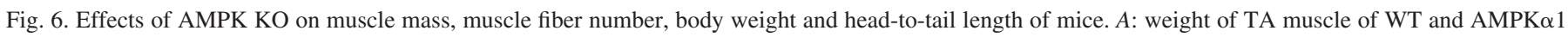

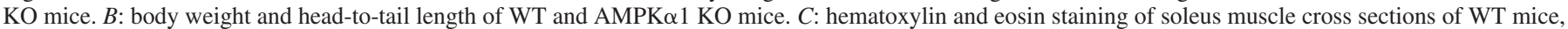

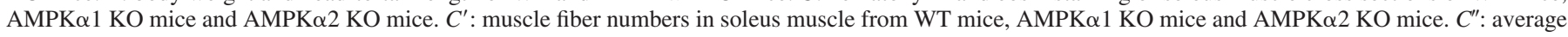

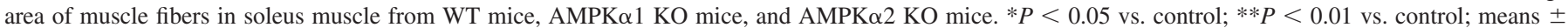
$\mathrm{SE} ; n \geq 3$.

of WT mice, and muscle fibers in AMPK $\alpha 1 \mathrm{KO}$ mice were $\sim 20 \%$ smaller in diameter than muscle fibers in WT mice (Fig. $6 C$ ). However, an increased muscle fiber diameter (Fig. 6C) and muscle mass (data not shown) was observed in AMPK $\alpha 2$ KO mice, albeit no change in muscle fiber number, which further suggests an AMPK $\alpha 1$-specific role in myogenesis.

\section{DISCUSSION}

Obesity and T2D are closely linked metabolic complications, both of which are increasing at alarming rates (34). Pathophysiological changes such as obesity and chronic inflammation are known to inhibit, rather than activate, AMPK (41), suggesting that inhibition, rather than activation, is more relevant to the pathophysiological roles of AMPK $(7,47)$. AMPK is phosphorylated by a constitutively active kinase, LKB1, which suggests that dephosphorylation rather than phosphorylation may be the main mechanism for regulating AMPK activity (39). In our previous studies, we observed that low AMPK activity correlated with impaired myogenesis (50), despite of undefined mechanisms.

To explore, we analyzed the structure of myogenin promoter and found a conserved MEF2 binding site on the myogenin promoter (17). It is well established that HDAC5 interacts with MEF2 to regulate gene expression $(24,25)$. We asked whether HDAC5 was involved in the regulation of myogenin expression. Indeed, HDAC5 knockdown increased H3K9 acetylation, which was associated with enhanced myogenin expression and myogenesis. We also treated $\mathrm{C} 2 \mathrm{C} 12$ cells with $\mathrm{MC} 1568$, which stabilizes the repressor structure of HDAC5 (30); consistently, the myogenin level and myogenesis were decreased. In addition, overexpression of HDAC5 in $\mathrm{C} 2 \mathrm{C} 12$ reduced myogenin content. In combination, these data indicate that HDAC5 negatively regulates myogenin transcription and myogenesis.

To further determine if HDAC5 directly regulates the transcriptional activity of the myogenin promoter, we cloned the myogenin promoter into pGL4 luciferase vector to construct a myogenin promoter-driven luciferase reporter. In line with above data, HDAC5 negatively regulates the transcriptional activity of myogenin promoter.

Phosphorylation of HDAC5 by protein kinases leads to its translocation from the nucleus to the cytoplasm. This represents a conserved mechanism by which HDAC class II family members regulate gene transcription (13). Our previous study showed that AMPK phosphorylates HDAC5 at Ser 259 and 498 , promoting its nuclear translocation to induce $\beta$-catenin expression (48). Consistently, experiment showed that phosphorylation of HDAC5 is reduced in AMPK $\alpha 1 \mathrm{KO}$ myoblasts. We then tested whether the phosphorylation of HDAC5 by AMPK also regulates myogenin expression.

AMPK contains two catalytic subunit isoforms, $\alpha 1$ and $\alpha 2$. To further test whether this regulation is in an isoform-specific manner, we separated primary myoblasts from WT, AMPK $\alpha 1$ 
$\mathrm{KO}$ mice, and AMPK $\alpha 2 \mathrm{KO}$ mice and induced fusion. AMPK $\alpha 1 \mathrm{KO}$ but not AMPK $\alpha 2 \mathrm{KO}$ (data not shown) dramatically reduced myotube formation. A reduced myogenin level was found in AMPK $\alpha 1 \mathrm{KO}$ muscle compared with WT muscle. In addition, overexpression of HDAC5 mutants abolished the effect AMPK $\alpha 1$ knockdown on myogenin expression, myogenin promoter activity, and myogenesis in $\mathrm{C} 2 \mathrm{C} 12$ cells. Furthermore, mutation of either HDAC5 Ser 259 or Ser 498 abolished the regulatory effects of AMPK $\alpha 1$ on myogenin in C2C12 cells, indicating that the phosphorylations of both Ser 259 and Ser 498 by AMPK $\alpha 1$ might be required for the efficient nuclear export of HDAC5.

Because RNA interference only partially knockdown AMPK catalytic $\alpha$-subunit, to clearly elucidate the role of AMPK $\alpha 1$ on myogenin expression, we isolated primary myoblasts from neonatal WT and AMPK $\alpha 1 \mathrm{KO}$ mice, and these myoblasts were transfected with myogenin promoter-luciferase vector or with HDAC5 WT or HDAC5 mutants (Ser 259 and Ser 498 to Ala). HDAC5 WT dramatically suppressed myogenin promoter activity in AMPK $\alpha 1 \mathrm{KO}$ compared with WT primary myoblasts, showing that the absence of AMPK $\alpha 1$ activity attenuates the inhibitory effect on HDAC5. These mutants (Ser259Ala, Ser498Ala, and DM) suppressed myogenin promoter activity in both AMPK $\alpha 1 \mathrm{KO}$ and WT myoblasts to a similar extent, showing that these sites are necessary for induction of HDAC5 translocation by AMPK $\alpha 1$.

Our observation that AMPK activity is necessary to promote myogenin expression and myogenesis via phosphorylation of HDAC5 has important physiological implications. The obesity epidemic is becoming increasingly serious, and it is well demonstrated that obesity inhibits AMPK activity via $\mathrm{TNF} \alpha$ (41). In addition, AMPK activity is also regulated by adipokines, such as leptin, adiponectin, and resistin, and cytokines, such as interleukin-6 (42). Therefore, obesity, inflammation, and other physiological factors that inhibit AMPK activity are likely to negatively affect myogenesis through downregulation of myogenin transcription, which may exert long-term negative effects on the mass and properties of skeletal muscle. Indeed, in this study, we observed that the fiber number in soleus muscle was reduced for $\sim 25 \%$ and muscle fiber diameter was reduced for $\sim 20 \%$ due to AMPK $\alpha 1 \mathrm{KO}$, and TA muscle was found to be $30 \%$ smaller in AMPK $\alpha 1 \mathrm{KO}$ mice than in WT mice, clearly showing the importance of AMPK in the regulation of myogenesis. In addition, a reduced body weight but a normal head-to-tail length was observed in AMPK $\alpha 1 \mathrm{KO}$, which could be mostly due to the reduced muscle mass. Hence, drugs activating AMPK, such as metformin, a common antidiabetic drug, can be used to activate AMPK to promote muscle development and regeneration. In addition, the demonstration of HDAC5 in the mediation of myogenin expression and myogenesis facilitates the exploration of HDAC5 inhibitors as additional chemical agents to enhance muscular development and regeneration, improving overall muscle properties. Interestingly, AMPK $\alpha 2 \mathrm{KO}$ was associated with increased muscle fiber diameter, which could be due to the inhibitory effects of AMPK $\alpha 2$ on protein synthesis suggesting that AMPK $\alpha 1$ and AMPK $\alpha 2$ have different roles in myogenesis and muscle hypertrophy (5).

In summary, AMPK phosphorylates HDAC5, which promotes the expression of myogenin and myogenesis. These data in combination with our previous observation in the regulation of $\beta$-catenin expression by HDAC5 (48) bring a uniform mechanisms linking AMPK to myogenesis through phosphorylation of HDAC5, a notion corroborated by the wide presence of MEF2 binding sites in the promoters of myogenic genes. Furthermore, in this study, we demonstrate that such promoting effect on myogenesis is mainly mediated by AMPK $\alpha 1$ subunit.

\section{GRANTS}

The work was supported by National Institute of Child Health and Human Development Grants 1R01-HD-067449 and 1R03-HD-057506 and US Department of Agriculture National Research Initiative Grant USDA-NRI-200835206-18826.

\section{DISCLOSURES}

No conflicts of interest, financial or otherwise, are declared by the author(s).

\section{AUTHOR CONTRIBUTIONS}

Author contributions: X.F., J.-X.Z., J.L., M.-J.Z., and B.V. performed experiments; X.F., J.-X.Z., J.L., and M.-J.Z. analyzed data; X.F. interpreted results of experiments; X.F. prepared figures; X.F. and M.D. drafted manuscript; J.-X.Z. and M.D. conception and design of research; B.V. and M.D. edited and revised manuscript; M.D. approved final version of manuscript.

\section{REFERENCES}

1. Aberle ED. Myofiber differentiation in skeletal muscles of newborn runt and normal weight pigs. J Anim Sci 59: 1651-1656, 1984.

2. Allen RE, Merkel RA, Young RB. Cellular aspects of muscle growth: myogenic cell proliferation. J Anim Sci 49: 115-127, 1979.

3. Bayol SA, Macharia R, Farrington SJ, Simbi BH, Stickland NC. Evidence that a maternal "junk food" diet during pregnancy and lactation can reduce muscle force in offspring. Eur J Nutr 48: 62-65, 2009.

4. Bertos NR, Wang AH, Yang XJ. Class II histone deacetylases: structure, function, and regulation. Biochem Cell Biol 79: 243-252, 2001.

5. Bolster DR, Crozier SJ, Kimball SR, Jefferson LS. AMP-activated protein kinase suppresses protein synthesis in rat skeletal muscle through downregulated mammalian target of rapamycin (mTOR) signaling. J Biol Chem 277: 23977-23980, 2002.

6. Brameld JM, Mostyn A, Dandrea J, Stephenson TJ, Dawson JM, Buttery PJ, Symonds ME. Maternal nutrition alters the expression of insulin-like growth factors in fetal sheep liver and skeletal muscle. $J$ Endocrinol 167: 429-437, 2000.

7. Brown KA, McInnes KJ, Hunger NI, Oakhill JS, Steinberg GR, Simpson ER. Subcellular localization of cyclic AMP-responsive element binding protein-regulated transcription coactivator 2 provides a link between obesity and breast cancer in postmenopausal women. Cancer Res 69: 5392-5399, 2009.

8. Brunetti A, Goldfine ID. Role of myogenin in myoblast differentiation and its regulation by fibroblast growth factor. J Biol Chem 265: $5960-$ 5963, 1990.

9. Decleves AE, Mathew AV, Cunard R, Sharma K. AMPK mediates the initiation of kidney disease induced by a high-fat diet. J Am Soc Nephrol 22: $1846-1855,2011$.

10. Dellavalle A, Maroli G, Covarello D, Azzoni E, Innocenzi A, Perani L, Antonini S, Sambasivan R, Brunelli S, Tajbakhsh S, Cossu G. Pericytes resident in postnatal skeletal muscle differentiate into muscle fibres and generate satellite cells. Nat Commun 2: 499, 2011.

11. Du M, Yan X, Tong JF, Zhao J, Zhu MJ. Maternal obesity, inflammation, and fetal skeletal muscle development. Biol Reprod 82: 4-12, 2010.

12. Flegal KM, Carroll MD, Kit BK, Ogden CL. Prevalence of obesity and trends in the distribution of body mass index among US adults, 19992010. JAMA 307: 491-497, 2012.

13. Grozinger CM, Schreiber SL. Regulation of histone deacetylase 4 and 5 and transcriptional activity by 14-3-3-dependent cellular localization. Proc Natl Acad Sci USA 97: 7835-7840, 2000.

14. Ha CH, Wang W, Jhun BS, Wong C, Hausser A, Pfizenmaier K, McKinsey TA, Olson EN, Jin ZG. Protein kinase D-dependent phosphorylation and nuclear export of histone deacetylase 5 mediates vascular endothelial growth factor-induced gene expression and angiogenesis. $J$ Biol Chem 283: 14590-14599, 2008. 
15. Handel SE, Stickland NC. The effects of low birthweight on the ultrastructural development of two myofibre types in the pig. J Anat 150: 129-143, 1987.

16. Hardie DG. AMP-activated protein kinase: a key system mediating metabolic responses to exercise. Med Sci Sports Exerc 36: 28-34, 2004.

17. Johanson M, Meents H, Ragge K, Buchberger A, Arnold HH, Sandmoller A. Transcriptional activation of the myogenin gene by MEF2mediated recruitment of myf5 is inhibited by adenovirus E1A protein. Biochem Biophys Res Commun 265: 222-232, 1999.

18. Jorgensen SB, Viollet B, Andreelli F, Frosig C, Birk JB, Schjerling P, Vaulont S, Richter EA, Wojtaszewski JF. Knockout of the alpha2 but not alpha1 5'-AMP-activated protein kinase isoform abolishes 5-aminoimidazole-4-carboxamide-1-beta-4-ribofuranosidebut not contraction-induced glucose uptake in skeletal muscle. J Biol Chem 279: 1070-1079, 2004.

19. Kim J, Solis RS, Arias EB, Cartee GD. Postcontraction insulin sensitivity: relationship with contraction protocol, glycogen concentration, and 5' AMP-activated protein kinase phosphorylation. J Appl Physiol 96: 575-583, 2004.

20. Ko HJ, Zhang Z, Jung DY, Jun JY, Ma Z, Jones KE, Chan SY, Kim JK. Nutrient stress activates inflammation and reduces glucose metabolism by suppressing AMP-activated protein kinase in the heart. Diabetes 58: 2536-2546, 2009 .

21. Lee RC, Wang ZM, Heymsfield SB. Skeletal muscle mass and aging: regional and whole-body measurement methods. Can J Appl Physiol 26: 102-122, 2001.

22. Lemercier C, Verdel A, Galloo B, Curtet S, Brocard MP, Khochbin S. mHDA1/HDAC5 histone deacetylase interacts with and represses MEF2A transcriptional activity. J Biol Chem 275: 15594-15599, 2000.

23. Lowell BB, Shulman GI. Mitochondrial dysfunction and type 2 diabetes. Science 307: 384-387, 2005.

24. Lu J, McKinsey TA, Zhang CL, Olson EN. Regulation of skeletal myogenesis by association of the MEF2 transcription factor with class II histone deacetylases. Mol Cell 6: 233-244, 2000.

25. McGee SL. Exercise and HDAC interactions. Appl Physiol Nutr Metab 32: 852-856, 2007.

26. McGee SL, van Denderen BJ, Howlett KF, Mollica J, Schertzer JD, Kemp BE, Hargreaves M. AMP-activated protein kinase regulates GLUT4 transcription by phosphorylating histone deacetylase 5. Diabetes 57: 860-867, 2008.

27. McKinsey TA, Zhang CL, Olson EN. Activation of the myocyte enhancer factor-2 transcription factor by calcium/calmodulin-dependent protein kinase-stimulated binding of 14-3-3 to histone deacetylase 5. Proc Natl Acad Sci USA 97: 14400-14405, 2000.

28. McKinsey TA, Zhang CL, Olson EN. Control of muscle development by dueling HATs and HDACs. Curr Opin Genet Dev 11: 497-504, 2001.

29. Milan D, Jeon JT, Looft C, Amarger V, Robic A, Thelander M, Rogel-Gaillard C, Paul S, Iannuccelli N, Rask L, Ronne H, Lundstrom K, Reinsch N, Gellin J, Kalm E, Roy PL, Chardon P, Andersson L. A mutation in PRKAG3 associated with excess glycogen content in pig skeletal muscle. Science 288: 1248-1251, 2000.

30. Nebbioso A, Manzo F, Miceli M, Conte M, Manente L, Baldi A, De Luca A, Rotili D, Valente S, Mai A, Usiello A, Gronemeyer H, Altucci L. Selective class II HDAC inhibitors impair myogenesis by modulating the stability and activity of HDAC-MEF2 complexes. EMBO Rep 10: 776-782, 2009.

31. Niesler CU, Myburgh KH, Moore F. The changing AMPK expression profile in differentiating mouse skeletal muscle myoblast cells helps confer increasing resistance to apoptosis. Exp Physiol 92: 207-217, 2007.

32. Park SK, Sheffler TL, Spurlock ME, Grant AL, Gerrard DE. Chronic activation of 5'-AMP-activated protein kinase changes myosin heavy chain expression in growing pigs. J Anim Sci 87: 3124-3133, 2009.

33. Perdiguero E, Sousa-Victor P, Ballestar E, Munoz-Canoves P. Epigenetic regulation of myogenesis. Epigenetics 4: 541-550, 2009.
34. Petersen KF, Dufour S, Shulman GI. Decreased insulin-stimulated ATP synthesis and phosphate transport in muscle of insulin-resistant offspring of type 2 diabetic parents. PLoS Med 2: e233, 2005.

35. Rando TA, Blau HM. Primary mouse myoblast purification, characterization, and transplantation for cell-mediated gene therapy. J Cell Biol 125: 1275-1287, 1994.

36. Ruderman NB, Xu XJ, Nelson L, Cacicedo JM, Saha AK, Lan F, Ido Y. AMPK and SIRT1: a long-standing partnership? Am J Physiol Endocrinol Metab 298: E751-E760, 2010.

37. Rudnicki MA, Le Grand F, McKinnell I, Kuang S. The molecular regulation of muscle stem cell function. Cold Spring Harb Symp Quant Biol 73: 323-331, 2008.

38. Saccone V, Puri PL. Epigenetic regulation of skeletal myogenesis. Organogenesis 6: 48-53, 2010.

39. Sakamoto K, Goransson O, Hardie DG, Alessi DR. Activity of LKB1 and AMPK-related kinases in skeletal muscle: effects of contraction, phenformin, and AICAR. Am J Physiol Endocrinol Metab 287: E310E317, 2004.

40. Selvi RB, Kundu TK. Reversible acetylation of chromatin: implication in regulation of gene expression, disease and therapeutics. Biotechnol J 4: 375-390, 2009.

41. Steinberg GR, Michell BJ, van Denderen BJ, Watt MJ, Carey AL, Fam BC, Andrikopoulos S, Proietto J, Gorgun CZ, Carling D, Hotamisligil GS, Febbraio MA, Kay TW, Kemp BE. Tumor necrosis factor alpha-induced skeletal muscle insulin resistance involves suppression of AMP-kinase signaling. Cell Metab 4: 465-474, 2006.

42. Steinberg GR, Watt MJ, Febbraio MA. Cytokine Regulation of AMPK signalling. Front Biosci 14: 1902-1916, 2009.

43. Tong JF, Yan X, Zhao JX, Nathanielsz PW, Du M. Metformin mitigates the impaired development of skeletal muscle in the offspring of obese mice. Nutr Diabetes 1: e7, 2011.

44. Viollet B, Andreelli F, Jorgensen SB, Perrin C, Geloen A, Flamez D, Mu J, Lenzner C, Baud O, Bennoun M, Gomas E, Nicolas G, Wojtaszewski JF, Kahn A, Carling D, Schuit FC, Birnbaum MJ, Richter EA, Burcelin R, Vaulont S. The AMP-activated protein kinase alpha2 catalytic subunit controls whole-body insulin sensitivity. J Clin Invest 111: 91-98, 2003.

45. Viollet B, Athea Y, Mounier R, Guigas B, Zarrinpashneh E, Horman S, Lantier L, Hebrard S, Devin-Leclerc J, Beauloye C, Foretz M, Andreelli F, Ventura-Clapier R, Bertrand L. AMPK: Lessons from transgenic and knockout animals. Front Biosci 14: 19-44, 2009.

46. Yan X, Zhu MJ, Xu W, Tong JF, Ford SP, Nathanielsz PW, Du M. Up-regulation of Toll-like receptor 4/nuclear factor-kappaB signaling is associated with enhanced adipogenesis and insulin resistance in fetal skeletal muscle of obese sheep at late gestation. Endocrinology 151: 380-387, 2010.

47. Yang Z, Kahn BB, Shi H, Xue BZ. Macrophage alpha1 AMP-activated protein kinase (alpha1AMPK) antagonizes fatty acid-induced inflammation through SIRT1. J Biol Chem 285: 19051-19059, 2010.

48. Zhao JX, Yue WF, Zhu MJ, Du M. AMP-activated protein kinase regulates beta-catenin transcription via histone deacetylase 5. J Biol Chem 286: 16426-16434, 2011.

49. Zhu MJ, Han B, Tong J, Ma C, Kimzey JM, Underwood KR, Xiao Y, Hess BW, Ford SP, Nathanielsz PW, Du M. AMP-activated protein kinase signalling pathways are down regulated and skeletal muscle development impaired in fetuses of obese, over-nourished sheep. J Physiol 586: 2651-2664, 2008.

50. Zhu MJ, Han B, Tong J, Ma C, Kimzey JM, Underwood KR, Xiao Y, Hess BW, Ford SP, Nathanielsz PW, Du M. AMP-activated protein kinase signalling pathways are down regulated and skeletal muscle development impaired in fetuses of obese, over-nourished sheep. J Physiol 586: 2651-2664, 2008. 